\title{
Selective Catalytic Reduction of Nitric Oxide by Ammonia: The Activation Mechanism
}

\author{
Yuka Kobayashi,* Nobuo Tajima, Haruyuki Nakano, and Kimihiko Hirao \\ Department of Applied Chemistry, School of Engineering, The University of Tokyo, \\ Hongo 7-3-1, Bunkyo-ku, Tokyo, 113-8656 Japan
}

Received: May 12, 2004; In Final Form: June 25, 2004

\begin{abstract}
The activation mechanism of $\mathrm{NH}_{3}$ in the selective catalytic reduction of $\mathrm{NO}$ by $\mathrm{NH}_{3}$ on a $\mathrm{V}_{2} \mathrm{O}_{7} \mathrm{H}_{4}$ cluster was investigated using a complete active space self-consistent field method. Because of the easy bond dissociation of $\mathrm{NH}_{4}{ }^{+}$adsorbed on Brønsted acid sites of the $\mathrm{V}_{2} \mathrm{O}_{5}$ configuration, the radical species $\mathrm{NH}_{3}{ }^{+}$can occur with an activation energy of only $26.7 \mathrm{kcal} / \mathrm{mol}$. The highly active intermediate $\mathrm{NH}_{3}{ }^{+}$is stabilized by forming a very strong hydrogen bond of approximately $29.2 \mathrm{kcal} / \mathrm{mol}$ to the vanadyl oxygen. This stabilization mechanism is very similar to the low-barrier hydrogen bond in the transition state, or in an unstable intermediate state, which has been reported for some enzymatic reactions.
\end{abstract}

In recent decades, the problem of air pollution and acid rain, caused by toxic gases such as $\mathrm{NO}_{x}$ and $\mathrm{SO}_{x}$, has become ecologically serious. ${ }^{1}$ The technique of decomposing $\mathrm{NO}_{x}$ with the selective catalytic reduction (SCR) of $\mathrm{NO}$ by $\mathrm{NH}_{3}$ over vanadia-based catalysts is very effective. This method, which was established in the 1970s, is still the major strategy for the reduction of NO industrially. Therefore, considerable effort has been spent in elucidating the reaction processes of the SCR, and many different schemes have been suggested in the literature. $^{2}$ However, the development of a next-generation catalyst demands a deep understanding of the reaction mechanisms of the SCR.

Experiments have proven that $\mathrm{NO}$ and $\mathrm{N}_{2}$ are only weakly adsorbed on a $\mathrm{V}_{2} \mathrm{O}_{5}$ surface. In contrast, $\mathrm{NH}_{3}$ has been reported to be readily absorbed on the surface of Brønsted acid sites of $\mathrm{V}_{2} \mathrm{O}_{5} \cdot{ }^{3,4}$ These observations lead to the conclusion that the SCR reaction can be described by the Eley-Rideal mechanism involving adsorbed $\mathrm{NH}_{3}$ species and gas-phase NO. ${ }^{5}$ The experimental evidence has been that both the $\mathrm{V}-\mathrm{OH}$ (Brønsted acid sites) and the $\mathrm{V}=\mathrm{O}$ species of a $\mathrm{V}_{2} \mathrm{O}_{5}$ surface are crucial for conversion of $\mathrm{NO}_{x} \cdot{ }^{6}$ In situ Fourier transfrom IR (FTIR) and on-line mass spectroscopic studies have shown that $\mathrm{NH}_{4}{ }^{+}$ is the predominant species on vanadia/titania catalysts under SCR conditions. ${ }^{7}$ However, no direct observation of a NOreacting species has been reported in any experiment. The identification of the active species is clearly one of the most important, and challenging, subjects left in order to explain the reaction mechanism of SCR. $\mathrm{NH}_{3}$ adsorbed at Brønsted acid sites has been reported to form $\mathrm{NH}_{4}{ }^{+}$species. ${ }^{7}$ This suggests that the adsorbed ammonia never interacts directly with NO. At high temperatures $\left(>300{ }^{\circ} \mathrm{C}\right), \mathrm{NH}_{2}$ is considered to be the activated species in the thermal decomposition of NO ${ }^{8}$ Because $\mathrm{NH}_{2} \mathrm{NO}$, which is produced when $\mathrm{NH}_{2}$ and $\mathrm{NO}$ combine, has never been detected under SCR conditions on a $\mathrm{V}=\mathrm{O}$, it cannot be considered a key molecule. ${ }^{9} \mathrm{NH}_{4}{ }^{+}$and $\mathrm{NH}_{3}{ }^{+}$have been suggested as the activated species in SCR. ${ }^{10,6}$ Recently, our group investigated the reactivity of $\mathrm{NH}_{4}{ }^{+}$and $\mathrm{NH}_{3}{ }^{+}$with $\mathrm{NO}$ under gas-phase conditions using a second-order multireference

* To whom correspondence may be addressed. E-mail: yuka@ chiral.t.utokyo.ac.jp. Fax: +81-3-5841-7267. Current address: Department of Chemistry and Biotechnology, School of Engineering, The University of Tokyo, Hongo 7-3-1, Bunkyo-ku, Tokyo 113-8656, Japan. perturbation method. ${ }^{11}$ In that study, a large difference in the energy profile of the initial $\mathrm{N}-\mathrm{N}$ bond formation step was observed. In the first $\mathrm{N}-\mathrm{N}$ bond intermediate produced by $\mathrm{NH}_{4}{ }^{+}$ and $\mathrm{NO}$, the $\mathrm{N}-\mathrm{N}$ bond is very unstable because one electron occupies its antibonding orbital. Therefore, a large amount of energy $(71.4 \mathrm{kcal} / \mathrm{mol})$ is required to form the $\mathrm{N}-\mathrm{N}$ bond complex, which indicates a low reactivity. Conversely, NO reacts with $\mathrm{NH}_{3}{ }^{+}$exothermically and forms a relatively stable $\mathrm{N}-\mathrm{N}$ coordination bond, where the radical electron is transferred from $\mathrm{NO}$ to $\mathrm{NH}_{3}{ }^{+}$. The resulting complex is produced without any activation barrier so that $\mathrm{NH}_{3}{ }^{+}$is expected to decompose $\mathrm{NO}$ efficiently on the $\mathrm{V}_{2} \mathrm{O}_{5}$ surface. However, in the gas phase, $\mathrm{NH}_{3}{ }^{+}$has a much higher total energy than $\mathrm{NH}_{4}{ }^{+}$. In the present study, we theoretically investigated these total energies at the $\mathrm{V}_{2} \mathrm{O}_{5}$ surface model.

Recently several groups are investigating the behavior of $\mathrm{NH}_{4}{ }^{+}$on the catalyst. A wide range of adsorption energy of $\mathrm{NH}_{4}{ }^{+}$is proposed on the basis of various surface models, e.g., $\mathrm{VO}_{3} \mathrm{H}_{3}, \mathrm{~V}_{2} \mathrm{O}_{7} \mathrm{H}_{4}, \mathrm{~V}_{2} \mathrm{O}_{9} \mathrm{H}_{8}$, and $\mathrm{V}_{4} \mathrm{O}_{16} \mathrm{H}_{12}$, etc., using various theoretical methods. ${ }^{12}$ However, crystal structure shows that the coordination environment of the $\mathrm{V}$ atom is tetrahedral and that the oxidation number is $+5 .{ }^{13}$ The simple $\mathrm{V}_{2} \mathrm{O}_{7} \mathrm{H}_{4}$ cluster model is more reasonable to describe the (010) surface of the $\mathrm{V}_{2} \mathrm{O}_{5}$ crystal, although this model has never been reported successful adsorption energy of $\mathrm{NH}_{4}{ }^{+}$so far. The difficulty in modeling this system originates from the $\mathrm{V}=\mathrm{O}$ double bond. A complicated electronic structure arises because of the d orbitals of the $\mathrm{V}$ atom. A complete active-space self-consistent field method (CASSCF) represents the $\pi$-bonding system in a manner that allows the electrostatic correlation to be treated with high accuracy. ${ }^{14}$ The breakdown of the mean-field approximation, which was observed in applying Hartree-Fock (HF) and density functional theory (DFT), can be avoided. We herein demonstrate the adsorption energy and possibility of the existence of unstable intermediate, $\mathrm{NH}_{3}{ }^{+}$, on the surface using $\mathrm{V}_{2} \mathrm{O}_{7} \mathrm{H}_{4}$ model by means of the method based on multiconfiguration.

\section{Computational Details}

All geometries, which are not defined in the text, were optimized using 3-21G basis sets. ${ }^{15}$ The determined structures were evaluated using the following basis sets: SBKJC VDZ 
a)

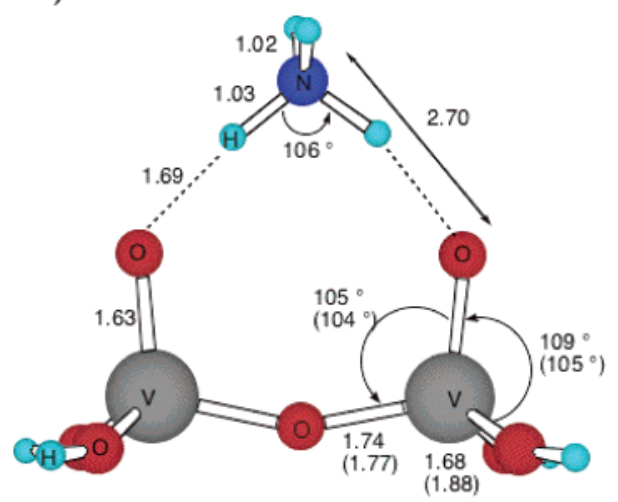

b)

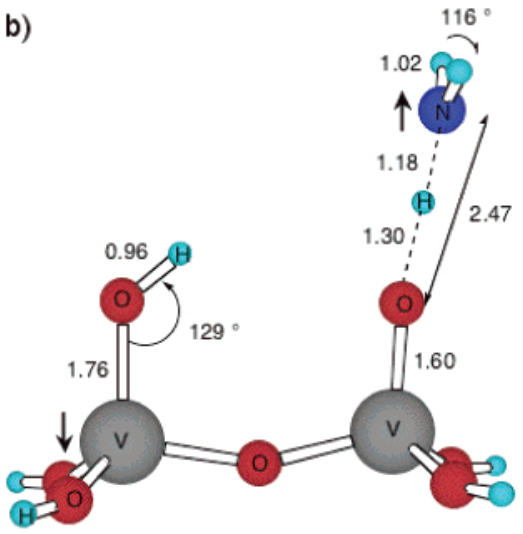

Figure 1. The adsorption structures of $\mathrm{NH}_{4}{ }^{+}$and $\mathrm{NH}_{3}{ }^{+}$on a $\mathrm{V}_{2} \mathrm{O}_{7} \mathrm{H}_{4}$ cluster are shown in (a) and (b), respectively. Bond lengths are shown in angstroms, and the angles in parentheses show experimental values. Bold arrows mean electron spins and hushed lines show hydrogen bonds. (a) The $\mathrm{NH}_{4}{ }^{+}$adsorbs in a nearly symmetrical fashion at the two $\mathrm{V}=\mathrm{O}$ sites (Brønsted acid sites) by hydrogen bonds. (b) After dissociation, the $\mathrm{NH}_{3}{ }^{+}$ stands on the $\mathrm{V}=\mathrm{O}$ site with a strong hydrogen bond.

ECP plus polarization for the $\mathrm{V}$ atoms; ${ }^{16}$ cc-pVDZ for the $\mathrm{O}$ atoms of $\mathrm{V}=\mathrm{O}$ sites; ${ }^{17} \mathrm{cc}-\mathrm{pVDZ}$ for the $\mathrm{N}$ and $\mathrm{H}$ atoms of the $\mathrm{NH}_{4}{ }^{+}$and $\mathrm{NH}_{3}{ }^{+} ; 3-21 \mathrm{G}$ for all other atoms. For the $\mathrm{V}_{2} \mathrm{O}_{7} \mathrm{H}_{4}$ cluster, the active space was chosen as [8e,8o], which includes 2 pairs of $\mathrm{d} \pi$ orbitals for each $\mathrm{V}=\mathrm{O}$ site. For the supermolecule of $\mathrm{NH}_{4}{ }^{+}$on the $\mathrm{V}_{2} \mathrm{O}_{7} \mathrm{H}_{4}$ cluster, [12e,12o], namely, [4e,4o] for two $\mathrm{N}-\mathrm{H}$ bonds of the $\mathrm{NH}_{4}{ }^{+}$which are in interaction with the $\mathrm{V}=\mathrm{O}$, and $[8 \mathrm{e}, 8 \mathrm{o}]$ for the two $\mathrm{V}=\mathrm{O}$ sites was chosen. All calculations were performed using the ab initio quantum chemistry package GAMESS. ${ }^{18}$

\section{Results and Discussion}

To examine the bonding property of $\mathrm{V}=\mathrm{O}$, we calculated the $\mathrm{V}_{2} \mathrm{O}_{7} \mathrm{H}_{4}$ cluster with CASSCF[6e,9o] /3-21G using the structures, which is determined by $\mathrm{ROHF} / 3-21 \mathrm{G}$ in singlet and triplet, respectively. ${ }^{19}$ As a result, $\mathrm{V}_{2} \mathrm{O}_{7} \mathrm{H}_{4}$ cluster in the singlet state is more stable as $38.5 \mathrm{kcal} / \mathrm{mol}$ than that in the triplet state. This calculation clarified that $\mathrm{V}=\mathrm{O}$ bond has quite multiconfigurational character in both states. The weight of the main electronic configuration is only $85 \%$; the rest of the configuration consists of $\mathrm{d} \pi-\mathrm{d} \pi^{*}$ and $\mathrm{d} \sigma-\mathrm{d} \sigma^{*}$ contributions, even in the ground state, as shown in Table 1. The bond length of the terminal vanadyl groups $(\mathrm{V}=\mathrm{O})$ was reoptimized with CASSCF$[8 \mathrm{e}, 8 \mathrm{o}] / 3-21 \mathrm{G}$ and found that it was $1.63 \AA$. This is marginally longer than the experimental value for a $\mathrm{V}_{2} \mathrm{O}_{5}$ single crystal $(1.58 \AA)$, measured by X-ray diffraction. ${ }^{13}$ Theoretical investigations on vanadyl, which is 3 -fold and 4-fold coordinated with oxygen, show only marginal changes in the $\mathrm{V}=\mathrm{O}$ bond length. The difference of adsorption energy between the experimental and theoretical results is a good measure for estimating the quality of a calculation. CASSCF[12e,12o] yields $E_{\text {ads }}\left(\mathrm{NH}_{4}{ }^{+}\right)$ $=24.7 \mathrm{kcal} / \mathrm{mol}$ as the $\mathrm{NH}_{4}{ }^{+}$adsorption energy to the $\mathrm{V}_{2} \mathrm{O}_{7} \mathrm{H}_{4}$ cluster, which is in good agreement with $18-26 \mathrm{kcal} / \mathrm{mol}$, observed in the experiment. ${ }^{20}$ On the other hand, DFT gives too large adsorption energy for $\mathrm{V}_{2} \mathrm{O}_{7} \mathrm{H}_{4}$; the values are in $\sim 50-$ $60 \mathrm{kcal} / \mathrm{mol}$, although it gives a reasonable value for $\mathrm{V}_{2} \mathrm{O}_{9} \mathrm{H}_{4}$, in which $\mathrm{V}^{5+}$ is not preserved.

The potential-energy surface (PES) of the reaction $\mathrm{NH}_{4}{ }^{+} \rightarrow$ $\mathrm{NH}_{3}{ }^{+}+\mathrm{H}$ in the gas phase was investigated using CASSCF$[8 \mathrm{e}, 8 \mathrm{o}] / \mathrm{cc}-\mathrm{pVDZ}$ prior to the surface reaction. ${ }^{21}$ This revealed that the potential energy increased monotonically with the $\mathrm{NH}_{3}{ }^{+}$ to $\mathrm{H}$ distance, that there was no transition state to produce $\mathrm{NH}_{3}{ }^{+}$, and also that the energy difference between the reactant $\mathrm{NH}_{4}{ }^{+}$ and the product $\left(\mathrm{NH}_{3}^{+}+\mathrm{H}\right)$ is as large as $\left(E_{\text {diss(gas })}=123.7\right.$
TABLE 1: Main and Minor Configurations in CASSCF[6e,9o] Wavefunctions of the $\mathrm{V}_{2} \mathrm{O}_{7} \mathrm{H}_{4}$ Cluster in Singlet and Triplet States

\begin{tabular}{ccccc}
\hline & $\begin{array}{c}\text { major } \\
\text { configuration }^{a}\end{array}$ & ratio (\%) & $\begin{array}{c}\text { major } \\
\text { configuration }^{b}\end{array}$ & ratio (\%) \\
\hline $\mathrm{V}_{2} \mathrm{O}_{7} \mathrm{H}_{4}$ & $\mathrm{~d} \pi(2)$ & 84.9 & $\mathrm{~d} \pi(2) \rightarrow \mathrm{d} \pi^{*}(1)$ & 1.7 \\
(singlet) & & & & \\
& $\mathrm{d} \sigma(2)$ & & $\mathrm{d} \pi(2) \rightarrow \mathrm{d} \pi^{*}(1)$ & 1.2 \\
& $\mathrm{~d} \pi(2)$ & & $\mathrm{d} \sigma(2) \rightarrow \mathrm{d} \sigma^{*}(1)$ & 1.1 \\
& & & $\mathrm{~d} \pi(2) \rightarrow \mathrm{d} \pi^{*}(1)$ & 1.1 \\
& & & $\mathrm{~d} \sigma(2) \rightarrow \mathrm{d} \sigma^{*}(1)$ & \\
& & & $\mathrm{d} \pi(2) \rightarrow \mathrm{d} \pi^{*}(1)$ & 1.0 \\
$\mathrm{~V}_{2} \mathrm{O}_{7} \mathrm{H}_{4}$ & $\mathrm{~d} \pi(2)$ & 19.0 & $\mathrm{~d} \sigma(2) \rightarrow \mathrm{d} \sigma^{*}(1)$ & \\
$($ triplet) & & & $\mathrm{O}: 2 \mathrm{p}(1)$ & 22.1 \\
& $\mathrm{~d} \sigma(2)$ & & $\mathrm{d} \pi(2) \rightarrow \mathrm{O}: 2 \mathrm{p}(1)$ & 10.0 \\
& $\mathrm{O}: 2 \mathrm{p}(1)$ & & $\mathrm{d} \sigma(2) \rightarrow \mathrm{V}: 3 \mathrm{~d}(1)$ & 8.6 \\
& $\mathrm{~V}: 3 \mathrm{~d}(1)$ & & $\mathrm{d} \sigma(2) \rightarrow \mathrm{V}: 3 \mathrm{~d}(1)$ & 7.5 \\
& & $\mathrm{~d} \pi(2) \rightarrow \mathrm{O}: 2 \mathrm{p}(1)$ & \\
& & $\mathrm{d} \sigma(2) \rightarrow \mathrm{O}: 2 \mathrm{p}(1)$ & 1.3 \\
& & $\mathrm{~d} \sigma(2) \rightarrow \mathrm{V}: 3 \mathrm{~d}(1)$ & \\
& & $\mathrm{d} \pi(2) \rightarrow \mathrm{O}: 2 \mathrm{p}(1)$ & 1.2 \\
& & $\mathrm{~d} \pi(2) \rightarrow \mathrm{d} \pi^{*}(1)$ & 1.1
\end{tabular}

${ }^{a}$ The occupied electron numbers are shown in parentheses. ${ }^{b} \mathrm{~Pa}-$ rentheses mean the excitation electron numbers from the main configurations. For example, $\mathrm{d} \pi(2) \rightarrow \mathrm{d} \pi^{*}(1)$ means one electron excitation configuration from doubly occupied $\mathrm{d} \pi$ orbital to $\mathrm{d} \pi^{*}$ orbital.

$\mathrm{kcal} / \mathrm{mol}$ ). This corresponds to the required energy for the production of $\mathrm{NH}_{3}{ }^{+}$in the gas phase, on an obviously unstable state.

Next, we examined the PES of $\mathrm{NH}_{4}{ }^{+}$on the $\mathrm{V}_{2} \mathrm{O}_{7} \mathrm{H}_{4}$ cluster. The bond dissociation of $\mathrm{NH}_{4}{ }^{+}$on the surface was investigated with CASSCF[12e,12o] using basis sets mentioned in the computational section. The optimized structures and the energy diagram of the dissociation of $\mathrm{NH}_{4}^{+}$on the surface are displayed in Figures 1 and 2, respectively. The theoretical representation of the dissociation products $\mathrm{V}=\mathrm{O} \cdot \mathrm{NH}_{3}{ }^{+}$and $\mathrm{V}-\mathrm{OH}$ are in an open-shell singlet state (Figure 1b). There is no activation barrier, which is similar to the result in the gas phase. The energy difference between the reactant and the product is $E_{\text {diss }}\left(\mathrm{V}_{2} \mathrm{O}_{7} \mathrm{H}_{4}\right)$ $=51.4 \mathrm{kcal} / \mathrm{mol}$. Although zero-point energy and entropic effects are not included in this calculation, these effects would not have a strong influence to the result. In a solid catalytic system, the real activation energy of the reaction is reduced by the heat of adsorption of the molecules on the catalytic surface (see Figure 2). ${ }^{22}$ Under SCR conditions, $\mathrm{NH}_{4}{ }^{+}$is the main adsorption species. ${ }^{10}$ It can be considered that most of its 


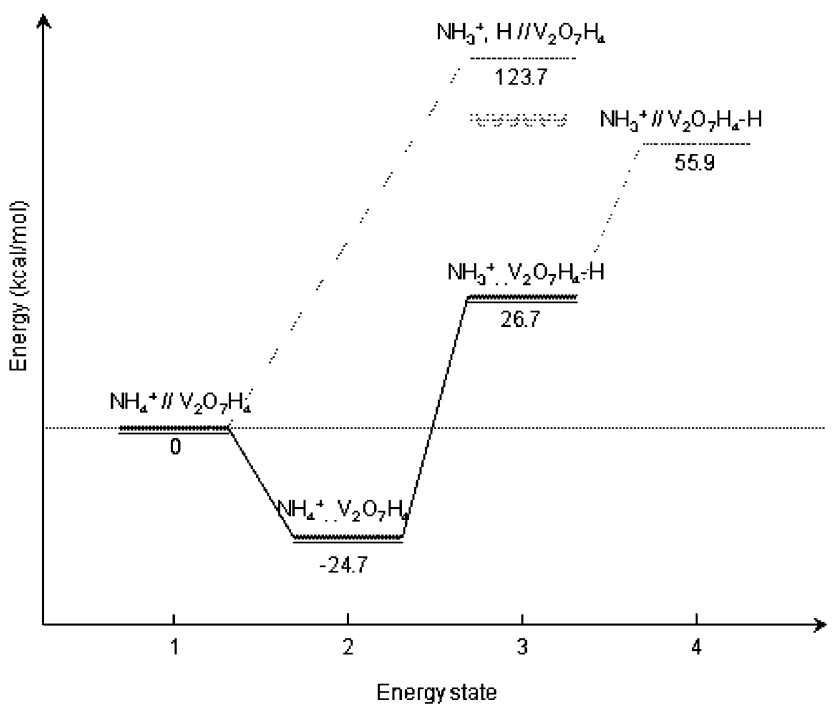

Figure 2. The energy diagram of the species on the $\mathrm{V}_{2} \mathrm{O}_{7} \mathrm{H}_{4}$ model, calculated with CASSCF[12e,12o]/SBKJC VDZ ECP plus polarization for the $\mathrm{V}$ atoms; cc-pVDZ for the $\mathrm{O}$ atoms of $\mathrm{V}=\mathrm{O}$ sites; cc-pVDZ for the $\mathrm{N}$ and $\mathrm{H}$ atoms of the $\mathrm{NH}_{4}{ }^{+}$and $\mathrm{NH}_{3}{ }^{+} ; 3-21 \mathrm{G}$ for all other atoms. State 1 is the reference energy level. It represents a $\mathrm{NH}_{4}^{+}$ molecule in the gas phase without any interaction to the $\mathrm{V}_{2} \mathrm{O}_{7} \mathrm{H}_{4}$. State 2 represents the adsorbed $\mathrm{NH}_{4}{ }^{+}$which relates to Figure 1a. Moving to state 3, the $\mathrm{V}_{2} \mathrm{O}_{7} \mathrm{H}_{4}$ abstracts one hydrogen atom from the $\mathrm{NH}_{4}{ }^{+}$. (Figure $1 \mathrm{~b}$ depicts the new configuration in detail.) For comparison, an activation energy of $E_{\text {diss(gas) }}=123.7 \mathrm{kcal} / \mathrm{mol}$ would be needed for a hydrogen dissociation reaction in the gas phase. State 4 indicates the binding energy of the $\mathrm{NH}_{3}{ }^{+}$to the $\mathrm{V}-\mathrm{O}$ of the $\mathrm{V}_{2} \mathrm{O}_{7} \mathrm{H}_{4}$. The energies are defined in the text.

adsorption energy is consumed in forming the activated species $\mathrm{NH}_{3}{ }^{+}$for the next reaction process. On the surface, a decrease of the required dissociation energy as great as $\Delta E_{\text {diss }}=E_{\text {diss(gas) }}$ $-E_{\text {diss }}\left(\mathrm{V}_{2} \mathrm{O}_{7} \mathrm{H}_{4}\right)=72.3 \mathrm{kcal} / \mathrm{mol}$, compared with the gas phase, can be obtained. Furthermore, the drastic reduction of the activation energy down to only $26.7 \mathrm{kcal} / \mathrm{mol}$ is due to two advantageous factors (see Figure 2). One is the high hydrogen affinity to the $\mathrm{V}=\mathrm{O}$ site of the surface. A CASSCF $[9 \mathrm{e}, 8 \mathrm{o}]$ calculation showed this to be $E_{(\mathrm{VO}-\mathrm{H})}=43.1 \mathrm{kcal} / \mathrm{mol} .{ }^{23}$ The other factor is the formation of a very strong hydrogen bond to the surface on the adsorption site of $\mathrm{NH}_{3}{ }^{+} . \mathrm{NH}_{4}{ }^{+}$adsorbs the two sites with ordinary hydrogen bonds, where the distance between the $\mathrm{N}$ atom and the $\mathrm{O}$ atoms of $\mathrm{V}=\mathrm{O}$ sites is $2.71 \AA$ (Figure 1a). On the other hand, $\mathrm{NH}_{3}{ }^{+}$stays on a $\mathrm{V}=\mathrm{O}$ site with a very strong hydrogen bond, this leads to an unusual short distance of $2.47 \AA$ between $\mathrm{N}$ and $\mathrm{O}$ atom and an extended $\mathrm{N}-\mathrm{H}$ bond (Figure $1 \mathrm{~b}$ ). The bond length of the $\mathrm{N} \cdots \mathrm{H}$ and the $\mathrm{H} \cdots \mathrm{O}$ are 1.18 and $1.30 \AA$, respectively. It should be noted that the $\mathrm{V}=\mathrm{O}$ site interacts with $\mathrm{NH}_{3}{ }^{+}$is shrunken to $1.60 \AA$ compared with the normal $\mathrm{V}=\mathrm{O}$ bond. This activation mechanism is strongly supported by in situ FTIR study, ${ }^{24}$ which shows that the peaks corresponds to $\mathrm{V}^{5+}-\mathrm{OH}$ and $\mathrm{V}^{4+}-\mathrm{OH}$, although the peaks of $\mathrm{NH}_{3}{ }^{+}$itself are difficult to be assigned. In the present system, the binding energy of the active intermediate $\mathrm{NH}_{3}{ }^{+}$on the surface model can be calculated by $E_{\text {ads }}\left(\mathrm{NH}_{3}{ }^{+}\right)=\Delta E_{\text {diss }}-E_{(\mathrm{VO}-\mathrm{H})}$. A remarkably high $E_{\text {ads }}\left(\mathrm{NH}_{3}{ }^{+}\right)$ value of $29.2 \mathrm{kcal} / \mathrm{mol}$, which forms a strong hydrogen bond, can be obtained.

The role of the strong hydrogen bond is similar to the biological hydrogen-bonding systems reported for some biological reaction processes. The unusually short hydrogen bonds are known as low-barrier hydrogen bonds (LBHB) or as short strong hydrogen bonds. LBHB has attracted considerable interest as an important factor in accelerating biochemical reactions, for example, in enzymes. ${ }^{25}$ In several enzymatic reactions, a LBHB is formed in the enzyme-substrate complex at a transition state and/or an intermediate, where it is considered that an energy of $10-20 \mathrm{kcal} / \mathrm{mol}$ is saved, the reaction is therefore significantly assisted. For example, on vanadium haloperoxidases, it has been suggested that the hydrogen bond formed between a $\mathrm{V}-\mathrm{O}$ site and its coordinated amino residues is significant in the catalytic mechanism. ${ }^{26}$

In this report, the energy profile of the key molecule $\mathrm{NH}_{3}{ }^{+}$ on the $\mathrm{V}_{2} \mathrm{O}_{5}$ surface in SCR was derived using an accurate $\mathrm{ab}$ initio molecular orbital method. The multiconfigurational character of the $\mathrm{V}=\mathrm{O}$ site is suitable to extract a hydrogen atom from the absorbed $\mathrm{NH}_{4}{ }^{+}$on the surface because of its high hydrogen affinity. Because of the contribution of the LBHB energy to the activated $\mathrm{V}=\mathrm{O}$ site, only $26.7 \mathrm{kcal} / \mathrm{mol}$ is required to produce an activated $\mathrm{NH}_{3}{ }^{+}$species. The role of the catalyst in SCR was revealed, and the beautiful similarity between the SCR and an enzymatic reaction mechanism with a LBHB was shown.

\section{References and Notes}

(1) Henry, J. G.; Heinke, G. W. Environmental Science and Engineering; Prentice-Hall: Englewood Cliffs, NJ, 1989.

(2) Busca, G.; Lietti, L.; Ramis, G.; Berti, F. Appl. Catal. B 1998, 18,

(3) Mitamoto, A.; Yamazaki, Y.; Hattori, T.; Inomata, M.; Murakami, Y. J. Catal. 1982, 74, 144. $64,259$.

(4) Ramis, G.; Busca, G.; Bregani, F.; Forzatti, P. Appl. Catal. 1990,

(5) Schneider, H.; Tschudin, S.; Schneider, M.; Wokaun, A.; Baiker, A. J. Catal. 1994, 147, 5 .

(6) Topsøe, N.-Y. Science 1994, 265, 1217.

(7) Topsøe, N.-Y.; Topsøe, H.; Dumesic, J. A. J. Catal. 1995, 151 226.

(8) Stief, L. J.; Brobst, W. D.; Nava, D. F.; Borkowski, R. P.; Michael, J. V. J. Chem. Soc., Faraday Trans. 2 1982, 78, 1391.

(9) Farber, M.; Harris, S. P. J. Phys. Chem. 1984, 88, 680.

(10) Miyamoto, A.; Yamazaki, Y.; Hattori, T.; Inomata, M.; Murakami, Y. J. Catal. 1982, 74, 144.

(11) Kobayashi, Y.; Tajima, N.; Hirao, K. J. Phys. Chem. A 2000, 104, 6855

(12) (a) Anstrom, M.; Topsøe, N.-Y.; Dumesic, J. A. J. Catal. 2003 , 213, 115. (b) Anstrom, M.; Dumesic, J. A.; Topsøe, N.-Y. Catal. Lett. 2002, 78, 281. (c) Yin, X.; Han, H.; Miyamoto, A. Phys. Chem. Chem. Phys. 2000, 2, 4243. (d) Gilardoni, F.; Weber, J.; Baiker, A. Int. Quantum Chem. 1997, 61, 683. (e) Gilardoni, F.; Weber, J.; Baiker, A. J. Phys. Chem. A 1997, 101, 6069 .

(13) Enjalbert, R.; Galy, J. Acta Cryst. 1986, C42, 1467.

(14) Roos, B. O. Int. J. Quantum Chem. 1980, S14, 175

(15) Binkley, J. S.; Pople, J. A.; Hehre, W. J. J. Am. Chem. Soc. 1980, 102,939 .

(16) Stevens, W. J.; Krauss, M.; Basch, H.; Jasien, P. G. Can. J. Chem. 1992, 70, 612

(17) Dunning, T. H., Jr. J. Chem. Phys. 1989, 90, 1007.

(18) Schmidt, M. W.; Baldridge, K. K.; Boatz, J. A.; Elbert, S. T ; Gordon, M. S.; Jensen, J. H.; Koseki, S.; Matsunaga, N.; Nguyen, K. A.; Su, S. J.; Windus, T. L.; Depuis, M.; Montgomery, J. A. J. Comput. Chem. $1993,14,1347$.

(19) The active space includes 3 pairs of electrons in 9 orbitals of one terminal $\mathrm{V}-\mathrm{O}$ site in $\mathrm{V}_{2} \mathrm{O}_{7} \mathrm{H}_{4}$ cluster to compare the energies between the two sites consistently. The $\mathrm{V}-\mathrm{O}$ bonds optimized with $\mathrm{ROHF} / 3-21 \mathrm{G}$ are $1.54 \AA$ in singlet, a value that is in good agreement with the experimental value $(1.58 \AA)$ and $1.83 \AA$ in the triplet state.

(20) Srmak, T. Z.; Dumesic, J. A.; Clausen, B. S.; Tornguist, E.; Topsøe, N.-Y. J. Catal. 1991, 135, 246.

(21) The active space was chosen as $[8 \mathrm{e}, 8 \mathrm{o}]$, which includes all valence orbitals of the $\mathrm{NH}_{4}^{+}$.

(22) Hinshelwood, C. N. The Kinetics of Chemical Change in Gaseous Systems; Oxford University Press: New York, 1926.

(23) The active space was that mentioned in the computational section plus additional one electron for the $\mathrm{H}$ atom.

(24) Topsøe, N.-Y.; Dumesic, J. A.; Topsøe, H. J. Catal. 1995, 151, 241.

(25) (a) Frey, P. A. Science 1995, 269, 104. (b) Cleland, W. W.; Kreevoy, M. M. Science 1994, 264, 1927.

(26) Butler, A. Coord. Chem. Rev. 1999, 87, 17. 